\title{
Lifestyle and socio-demographic factors associated with high-risk HPV infection in UK women
}

\author{
SC Cotton, ${ }^{*, 7}$, L Sharp ${ }^{2,7}$, R Seth ${ }^{3}$, LF Masson', J Little ${ }^{4}$, ME Cruickshank ${ }^{5}, K_{\text {Neal }}^{6}$ and N Waugh', on behalf of \\ the TOMBOLA Group
}

'Department of Public Health, University of Aberdeen, Polwarth Building, Foresterhill, Aberdeen, Scotland; ' National Cancer Registry Ireland, Elm Court, Boreenmanna Road, Cork, Ireland; ${ }^{3}$ Histopathology Department, Queen's Medical Centre, University Hospital NHS Trust, Nottingham, England; ${ }^{4}$ Canada Research Chair in Human Genome Epidemiology, Department of Epidemiology and Community Medicine, University of Ottawa, Ottawa, Ontario,

Canada; ${ }^{5}$ Department of Obstetrics \& Gynaecology, University of Aberdeen, Foresterhill, Aberdeen, Scotland; ${ }^{6}$ Division of Epidemiology and Public Health, School of Community Health Sciences, University of Nottingham Medical School, Nottingham, England

The world age-standardised prevalence of high-risk HPV (hrHPV) infection among 5038 UK women aged 20-59 years, with a lowgrade smear during 1999-2002, assessed for eligibility for TOMBOLA (Trial Of Management of Borderline and Other Low-grade Abnormal smears) was 34.2\%. High-risk HPV prevalence decreased with increasing age, from $61 \%$ at ages $20-24$ years to $14-15 \%$ in those over 50 years. The age-standardised prevalence was 15.I, 30.7 and 52.7\%, respectively, in women with a current normal, borderline nuclear abnormalities (BNA) and mild smear. In overall multivariate analyses, tertiary education, previous pregnancy and childbirth were associated with reduced hrHPV infection risk. Risk of infection was increased in non-white women, women not married/cohabiting, hormonal contraceptives users and current smokers. In stratified analyses, current smear status and age remained associated with hrHPV infection. Data of this type are relevant to the debate on human papillomavirus (HPV) testing in screening and development of HPV vaccination programmes.

British Journal of Cancer (2007) 97, I33-139. doi:I0.1038/sj.bjc.6603822 www.bjcancer.com

Published online 22 May 2007

(c) 2007 Cancer Research UK

Keywords: HPV infection; lifestyle factors; cervical cancer

Infection with human papillomavirus (HPV) is necessary for the development of cervical cancer (Walboomers et al, 1999; Bosch et al, 2002). Around $40 \mathrm{HPV}$ types infect mucosal surfaces of the lower genital area (International Agency for Research on Cancer, 2005) and are broadly classified into high- or low-risk for cervical cancer (Munoz et al, 2003). Testing for high-risk HPV (hrHPV) DNA has the potential to improve cervical screening (Brink et al, 2005). In addition, following encouraging trial results (Harper et al, 2004; Villa et al, 2005), two HPV vaccines are under licence. The effectiveness and cost-effectiveness of incorporating HPV testing into screening, and of vaccine programmes, will partly depend on current HPV prevalence, infection patterns and factors associated with infection within specific populations.

Human papillomavirus population prevalence mainly depends on patterns of sexual exchange (International Agency for Research on Cancer, 2005), which vary between and within countries, by, for example, birth cohort and ethnic group (Johnson et al, 2001; Fenton et al, 2005). Most available data on HPV prevalence and associated factors are from the United States of America, and/or focus on young women; many series are highly selective and may lack generalisibility. Other series did not examine lifestyle risk

\footnotetext{
*Correspondence: SC Cotton; E-mail: s.c.cotton@abdn.ac.uk

${ }^{7}$ Principal authors who contributed equally to this work.

Received 23 February 2007; revised 25 April 2007; accepted 2 May 2007; published online 22 May 2007
}

factors (e.g. Cuzick et al, 2003; Cuschieri et al, 2004; Moss et al, 2004; Hibbitts et al, 2006; Kitchener et al, 2006). Most infections in women under 30 are transient (Koutsky and Kiviat, 1999; Nobbenhuis et al, 2001; Woodman et al, 2001); infection risk factors, and/or their relative importance, may differ between young and older women. In addition, while cytological smear grade is strongly associated with HPV prevalence (Cuzick et al, 2003; Cuschieri et al, 2004), it is less clear whether the relative contribution of lifestyle risk factors differs by smear grade. We investigated factors associated with prevalence of hrHPV types in a large series of UK women and compared them in younger and older women and by cytological smear grade.

\section{MATERIALS AND METHODS}

\section{Study population}

Subjects were women assessed for eligibility for TOMBOLA (Trial Of Management of Borderline and Other Low-grade Abnormal smears), a randomised controlled trial (RCT) of alternative management policies and HPV triage (TOMBOLA Group, 2006).

Women aged 20-59 years, resident in Grampian, Tayside or Nottingham, with a low-grade smear (mild dyskaryosis or borderline nuclear abnormalities (BNA)) taken routinely in the UK national cervical screening programmes (CSPs) during 01/10/ 
1999-31/10/2003, with no previous treatment for cervical lesions, were eligible for TOMBOLA. Recruitment was in two phases: 01/ $10 / 1999-12 / 03 / 2001$ and $13 / 03 / 2001-31 / 10 / 2003$. During phase one, eligible women had no abnormal smears in the previous 3 years; during phase two, they had up to one BNA smear in the previous 3 years. In phase one, women with a BNA smear were invited to a recruitment clinic approximately 6 months later for a follow-up smear and a swab for HPV testing. Women with a mild smear during both phases, or a BNA smear during phase two, were invited to a recruitment clinic approximately 2 months later and a swab for HPV testing was taken. The swab, an endocervical sample, was taken with a cytobrush; this was immersed in $2 \mathrm{ml}$ of sterile phosphate-buffered saline containing $0.05 \%$ thiomersal.

A total of $52 \%$ of eligible women attended a recruitment clinic, of whom 95\% $(n=5514)$ consented to participate; 27 were subsequently excluded because the smear was inadequate. Five thousand and seventy-four (92\%) of the remainder provided an HPV sample.

Ethical approval was obtained from the joint Research Ethics Committee of NHS Grampian and the University of Aberdeen, the Tayside Committee on Medical Research Ethics and the Nottingham Research Ethics Committee. Participants provided informed consent.

\section{HPV testing}

Analysis was performed 1-4 weeks after swab collection in a single laboratory (Nottingham). Human and viral DNA were extracted using the Qiagen UK kit (Crawley, West Sussex, UK) (QIAamp ${ }^{\circledR}$ DNA Mini Kit) following optimisation of the manufacturer's protocol. Each batch included negative controls containing only elution buffer AE. Extracted DNA was amplified and quantitated by type-specific real-time polymerase chain reaction (PCR) for the housekeeping gene, human betaglobin. Samples without recordable DNA levels were considered inadequate $(n=36 ; 0.7 \%$ of 5074). Adequate samples underwent HPV PCR using GP5 + $6+$ consensus primers, followed by enzyme immunoassay for detection of 14 high-risk types $(16,18,31,33,35,39,45,51,52,56,58$, 59,66 and 68) (Jacobs et al, 1997). Women were considered hrHPV positive (hrHPV + ve) if their sample had an optical density (OD) three times greater than that of the batch-negative control, implying they carried at least one of the hrHPV strains. Other women were classified hrHPV negative (hrHPV-ve). Information was not available on individual HPV strains.

\section{Questionnaire}

At recruitment, all women completed a questionnaire on ethnic group, marital status, tertiary education, employment, reproductive factors, smoking and physical activity.

\section{Statistical analysis}

Women were classified by smear status, defined by their 'current' smear and any past BNA smear. For women with a BNA smear during recruitment phase one, this was considered the 'past' smear, while the 'current' smear was the recruitment smear (results ranged from normal to severe dyskaryosis). For other women, the 'current' smear was the smear that triggered the invitation to participate in TOMBOLA. Six smear status categories were defined: normal and one previous BNA; BNA and no previous abnormal; BNA and one previous BNA; mild and no previous abnormal; mild and one previous BNA; and moderate or severe dyskaryosis and one previous BNA.

Socio-demographic characteristics of women providing, and not providing, an HPV sample were compared using $\chi^{2}$-tests. Highrisk HPV prevalence was age-standardised to the truncated $(20-59$ years) world standard population. Multivariate unconditional logistic regression models were constructed to assess factors associated with hrHPV + ve risk. Since age modified the relationship between smear status and hrHPV status, these factors were fitted by a single variable, which combined the six smear status categories with two age groups (20-29 and $\geqslant 30$ years). The global likelihood ratio test (LRT) was used to assess the impact of lifestyle and socio-demographic factors on age-and-smear status-adjusted risk estimates; factors with $P<0.1$ were retained in the final model. To explore sub-group heterogeneity, the modelling was repeated stratifying by age (20-29 years; $\geqslant 30$ years) and current smear (normal; BNA; mild). All multivariate models had adequate fit (by the Hosmer and Lemeshow test; Hosmer and Lemeshow, 1989).

\section{RESULTS}

Younger women, white women and those with a single BNA or mild smear were less likely to provide an HPV sample than older women $\left(\chi_{3}^{2}=8.30, P=0.040\right)$, non-white ethnic groups $\left(\chi_{1}^{2}=8.19\right.$, $P=0.004)$ or those with a previous abnormal smear $\left(\chi_{5}^{2}=100.85\right.$, $P<0.001)$. Since two of three centres did not take swabs from menstruating women, the proportion providing a sample varied by centre $\left(\chi_{2}^{2}=294.53, P<0.001\right)$. It did not vary by tertiary education level $\left(\chi_{1}^{2}=0.34, P=0.559\right)$.

The crude hrHPV prevalence was $39.2 \%$ (95\% confidence interval (CI) 37.8-40.5). Positivity declined with increasing age (20-24 years $61.0 \%, 25-29$ years $50.1 \%$, $30-34$ years $39.6 \%$, 3539 years $30.6 \%$, $40-44$ years $22.0 \%, 45-49$ years $17.1 \%$ and $50-59$ years $14-15 \%)$, and increased with increasing smear grade. For all grades, prevalence and risk were higher in younger (20-29 years) than older ( $\geqslant 30$ years) women, but not by a constant amount (Figure 1; $P$ (interaction) 0.0004 ). The overall age-standardised prevalence was $34.2 \%$ (95\% CI 32.6-35.8). For women with a current normal smear, it was $15.1 \%$ (95\% CI 12.6-17.6), for those with a current BNA smear 30.7\% (95\% CI 8.6-32.8) and with a current mild smear $52.7 \%$ (95\% CI $48.6-56.8)$.

Other factors significantly associated with hrHPV status in multivariate analyses were tertiary education level, ethnic group, marital status, reproductive history, hormonal contraceptive use and smoking (Table 1). Women with a college/university degree were at reduced hrHPV + ve risk compared with those without a degree. Although prevalence varied little by ethnic group, in multivariate analyses, non-white women (e.g. black-African, Indian, Pakistani) were at significantly increased risk. Single, and divorced/separated/widowed, women had significantly higher infection risk than married/co-habiting women. High-risk HPV infection was associated with never being pregnant, having had children and age at first pregnancy, but not with number of children or caesarean delivery. Combining pregnancy, childbirth and age at first pregnancy (as 'reproductive history'), having a pregnancy resulting in childbirth was associated with lower infection risk, particularly for a first pregnancy at age $\geqslant 20$ years. Current and previous oral contraceptive (OC) use (combined or progesterone-only), and current use of other hormonal contraception (e.g. implants, injections, intrauterine system), were associated with increased risk. Compared with never smokers, current smokers (but not ex-smokers) were at a modest increased risk, unrelated to smoking pack-years (data not shown). Barrier contraception and physical activity were also unrelated to risk.

In multivariate age-stratified analyses of women aged 20-29 years, age and smear status were significantly associated with infection. Tertiary education and having had children were also significant risk factors, with risk estimates similar to those in unstratified analyses. In women aged 30-59 years, age and smear status were significantly associated with infection, as were tertiary education, having had children, ethnicity and smoking; effect sizes were similar to those in Table 1 . Other significant factors were marital status (increased risk in divorced/separated/widowed 


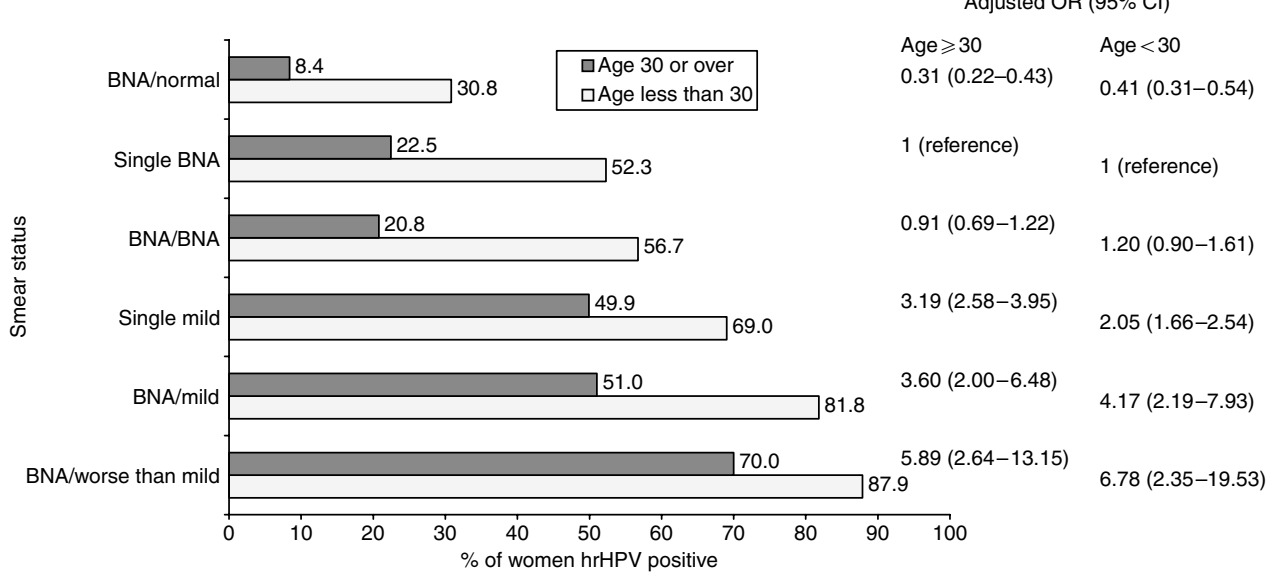

Figure I hr HPV positivity (\%) by smear status and age. BNA, smear showing BNA; mild, smear showing mild dyskaryosis; worse than mild, smear showing moderate or severe dyskaryosis; single BNA, women with a current BNA smear and no other BNA smear in previous 3 years; single mild, women with a current mild smear and no BNA smear in previous 3 years. Adjusted OR: adjusted for age (in women aged 30 years or over - 30-34, 35-59, 40-44, $45-49,50-54$ and $55-59$ years; in women aged less than 30 years $-20-24$ and $25-29$ years).

women (odds ratio (OR) 2.23, 95\% CI 1.79-2.79) and single women (OR 1.84, 95\% CI 1.35-2.50)), current hormonal contraceptive use (OR user vs non-user $1.30,95 \%$ CI $1.03-1.64$ ) and physical activity (OR active $v s$ not active $0.76,95 \%$ CI $0.60-0.97$ ).

In multivariate smear-stratified analyses of all smear groups, age was significantly associated with infection. Having a college/ university degree reduced infection risk in women with a current normal (OR 0.58, 95\% CI $0.34-0.99$ ) or BNA smear (OR 0.72, 95\% CI 0.56-0.91) but not in those with a mild smear. In all smear strata, divorced/separated/widowed women had higher risk than married/co-habiting women (normal OR 1.64, 95\% CI 0.91-2.96; BNA OR 2.26, 95\% CI 1.73-2.95; mild OR 2.12, 95\% CI 1.49-3.02). In the BNA strata only, being single also increased risk (OR 1.34, $95 \%$ CI $1.06-1.70)$. Having been pregnant was inversely associated with infection in those with a current normal (OR 0.60, 95\% CI $0.38-0.95$ ) or BNA smear (OR 0.81, 95\% CI 0.64-1.02), but not in those with a mild smear. Having had children was associated with reduced risk in all smear strata, only reaching statistical significance in the current normal group (OR 0.57, 95\% CI $0.36-$ 0.92 ). Hormonal contraceptive use was associated with increased risk in the current normal (OR 1.59, 95\% CI 1.02-2.48) and BNA (OR 1.29, 95\% CI 1.05-1.59) strata, but not among the mild group. Barrier contraceptive use, caesarean delivery, smoking, physical activity and ethnicity were unrelated to infection in all strata.

\section{DISCUSSION}

Our study was large, population-based and nested in a pragmatic RCT within the UK national CSPs. Among study participants, the current BNA : mild smear ratio $(1.8: 1)$ was close to that reported for the CSP screening age group in 2004-2005 (1.9:1) (NHS Health and Social Care Information Centre, 2005; ISD Scotland, 2007), suggesting our results are likely to be generalisable to women with low-grade smears.

While TOMBOLA participation was $52 \%$ overall, it was lower among younger women and those resident in more deprived areas (TOMBOLA Group, 2006), groups with increased HPV prevalence in this and other studies (Tonon et al, 1999; Cuzick et al, 2003; Winer and Koutsky, 2004). Thus, our crude hrHPV prevalence is likely to somewhat underestimate true prevalence among women with low-grade smears.

The treatment of lesions, and possibly also the act of taking a smear, can potentially clear cervical HPV infection (Shapiro et al,
2003; Sarian et al, 2005). Thus, hrHPV prevalence may be artificially lowered in populations with extensive screening coverage, such as the UK. Our participants had no previous treatment for cervical lesions and $66 \%$ had their last smear $\geqslant 3$ years before becoming eligible for TOMBOLA. Since hrHPV infection averages 8-14 months (Ho et al, 1998; Woodman et al, 2001), the effect of screening participation on our prevalence estimate is probably small.

A limitation of our study is that we did not collect information on numbers of sexual partners, age at first intercourse, etc, because of CSP guidelines (Duncan, 1997). Some factors we found to be associated with hrHPV infection may be markers of sexual behaviour. For example, smoking is associated with having had multiple sexual partners (Osler and Kjaer, 1996; Escobedo et al, 1997; Lam et al, 2001; Bellis et al, 2004; Jarvelaid, 2004), which is consistent with the observed raised infection risk among current smokers. UK rates of new partner acquisition vary by marital status, being highest among single or previously married women, intermediate among co-habiting women and lowest in married women (Johnson et al, 2001), a pattern compatible with our findings.

Our analyses extend existing knowledge on UK hrHPV prevalence, and are novel for Grampian and Tayside. Data from this and similar analyses will aid interpretation of studies of HPV testing in screening (e.g. Kitchener et al, 2006), and be valuable in modelling scenarios for alternative screening protocols, including HPV testing, as well as for policy makers in defining HPV vaccination strategies. It also provides a baseline against which the impact of vaccination on HPV infection patterns can be assessed in the future.

\section{Smear status}

Other than age, current smear grade was the strongest predictor of infection. In women with a current BNA smear, our hrHPV prevalence (crude $34.2 \%$, age-standardised $30.7 \%$ ) was similar to that among women with a BNA smear from the UK ARTISTIC trial (31\%) (Kitchener et al, 2006), but lower than (unstandardised) frequencies from other UK studies (46\%; Moss et al, 2004, 55\%; Hibbitts et al, 2006, 72\%; Cuschieri et al, 2004), and for women with ASCUS (atypical cells of undetermined significance) smears from the US ALTS trial (49\%; ALTS Group 2003). In the UK HART study, HPV prevalence among 289 women aged $30-60$ years with a current BNA smear was 27\% (Cuzick et al, 2003), close to the crude 
Table I Numbers and proportions of women hrHPV+ve and adjusted multivariate ORs for socio-demographic and lifestyle factors

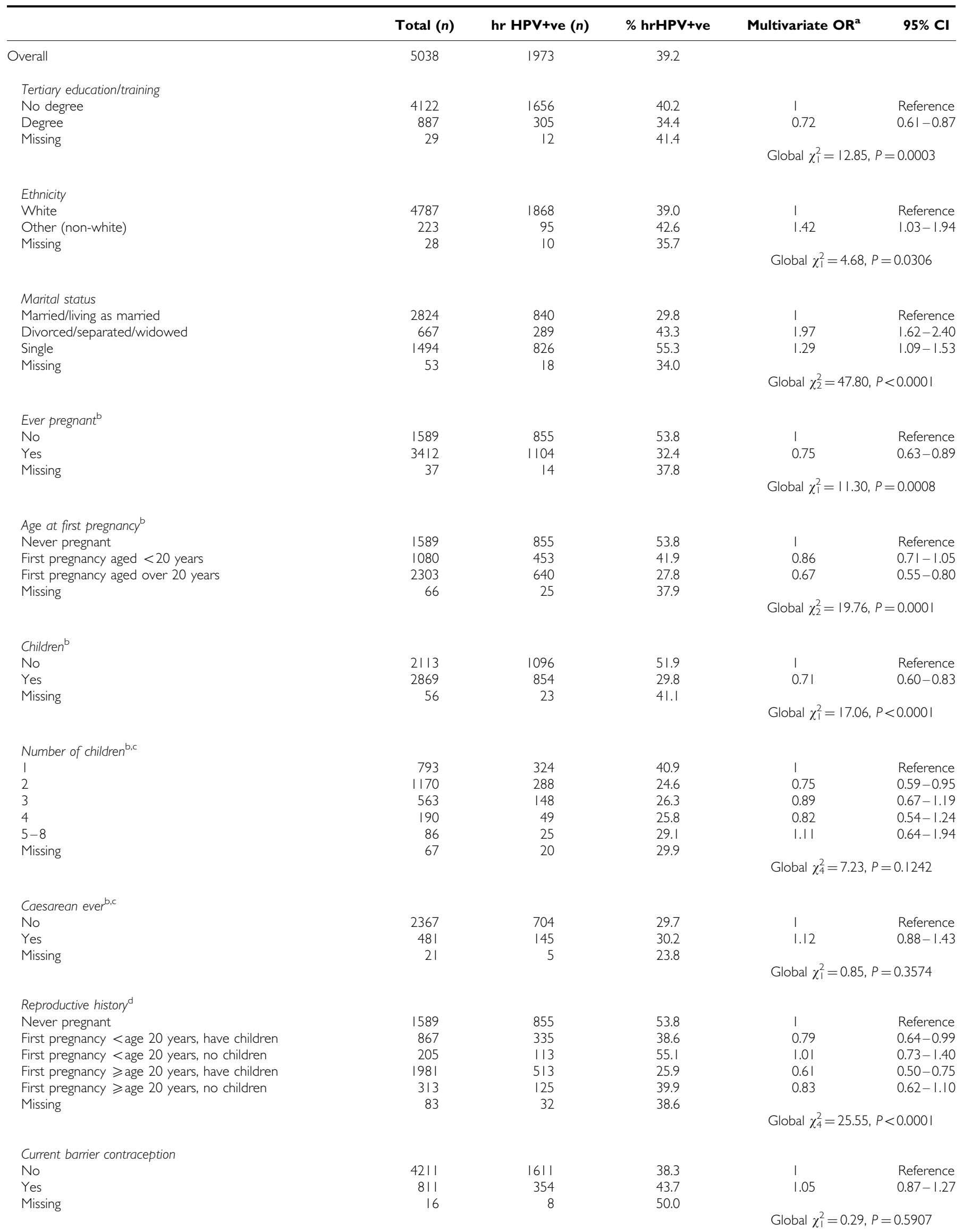




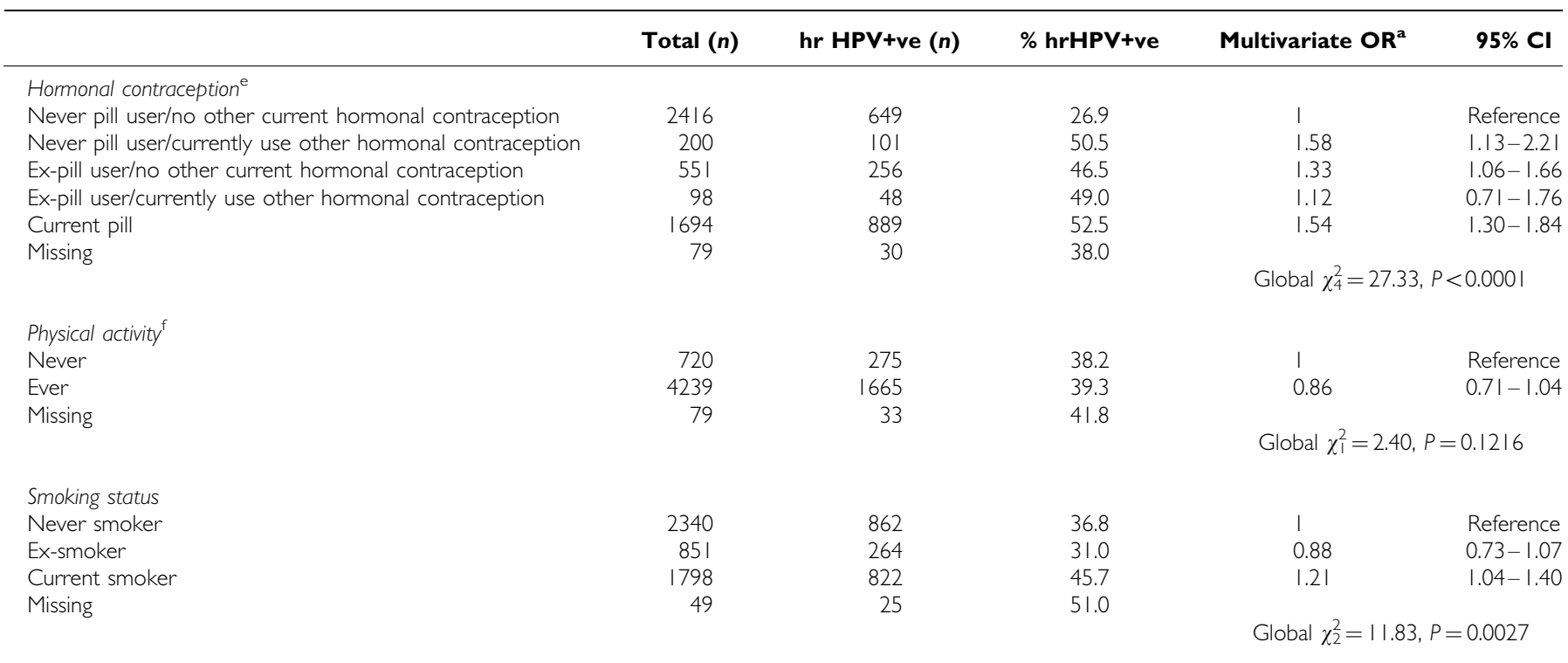

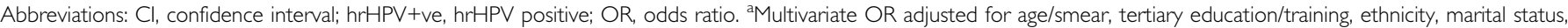
reproductive history, use of hormonal contraception and smoking status. 'Multivariate OR adjusted for age/smear, tertiary education/training, ethnicity, marital status, use of hormonal contraception and smoking status. 'Restricted to women who have had children. ${ }^{\mathrm{d}}$ Ever been pregnant, age at first pregnancy and ever had children were all individually associated with hrHPV. As these variables are related, a composite variable was created and fitted in model. "Women were classified into one of five categories on the basis of current use of oral contraceptive pill or other hormonal contraception, and on any previous oral contraceptive pill use. ${ }^{\mathrm{f}}$ There was no effect on risk of hrHPV of physical activity (never/ever) or of frequency of physical activity (data not shown).

prevalence among women $\geqslant 30$ years in our study $(26 \%)$. Our prevalence estimate among women with a current mild smear (crude $60.9 \%$, age-standardised $52.7 \%$ ) was also lower than nonstandardised estimates from the United Kingdom and the United States of America of at least 70\% (ALTS Group 2003; Moss et al, 2004; Hibbitts et al, 2006; Kitchener et al, 2006). In addition to different age profiles, comparison between studies is complicated by different HPV testing regimes (since tests detect different strains and vary in performance characteristics; Kulmala et al, 2004; Bosch and Iftner, 2005) and UK/USA differences in cytological abnormality classification.

Our crude $(16.0 \%)$ and age-standardised (15.1\%) prevalences among women with a current normal smear were similar to the pooled estimate from 27 PCR-based studies of cytologically normal women mainly from North America and Europe (16.2\%) (Xi and Koutsky, 1997). However, our figures were higher than in recent UK screening studies with normal cytology reporting unstandardised frequencies of 6-10\% (Cuzick et al, 2003; Cuschieri et al, 2004; Hibbitts et al, 2006; Kitchener et al, 2006). Our participants had had a previous BNA smear, which might inflate hrHPV prevalence, although among women with a current low-grade smear, having a previous BNA smear did not substantially increase prevalence (single BNA 34\%; BNA/BNA 35\%; single mild $60 \%$; BNA/mild 69\%). Our crude prevalence among women aged 30-59 years $(8.4 \%)$ was similar to that from the HART study $(6 \%)$ (Cuzick et al, 2003). Our age-standardised prevalence was similar to that for sexually active women aged 15-74 years from four countries in Latin America (12.4-17.7\%) and parts of Asia (China, Korea, India; $14.0-16.8 \%$ ), higher than for Vietnam and Thailand $(1.6-11.4 \%)$ and lower than for Nigeria (27.0\%) (Franceschi et al, 2006); these figures relate to $27 \mathrm{HPV}$ types, including 6 and 11.

\section{Age}

Notable geographical variations in age-specific HPV curves have recently been described (Franceschi et al, 2006). Our observation of decreasing hrHPV infection with increasing age (in all smear strata) is consistent with other UK, European and US series (Cuzick et al, 2003; Winer and Koutsky, 2004; Franceschi et al, 2006; Hibbitts et al, 2006).

\section{Ethnic group}

In the United Kingdom, white, black-African and black-Caribbean women have higher numbers of lifetime sexual partners, lower median age at first heterosexual intercourse and higher incidence of (non-HPV) sexually transmitted infections than women from Indian or Pakistani ethnic groups (Fenton et al, 2005). Although we observed increased infection risk among non-white ethnic groups, relatively few women described themselves thus $(n=223)$, precluding multivariate analysis of individual groups. Crude infection frequencies (Asian origin 35\%; white 39\%; black 45\%) are consistent with sexual behaviour data and suggest that the raised risk may be limited to black women.

\section{Contraception}

High-risk HPV infection risk was $>50 \%$ higher in women who had used OCs or other hormonal contraceptives. The latter have been studied little previously. Among ALTS participants, no association was found with injectable contraceptives or Norplant (Castle et al, 2005). Previous studies of OC use have been inconsistent (Green et al, 2003; Winer and Koutsky, 2004; Vaccarella et al, 2006a), perhaps due to differences in study design, types of OCs used/ assessed, prevalence of use and adjustment factors. While OC use may simply be a marker for 'high-risk' sexual behaviours (Winer and Koutsky, 2004), in several studies the OC-hrHPV association persisted after adjustment for factors such as number of sexual partners (Ley et al, 1991; Sikstrom et al, 1995; Winer et al, 2003). In further analyses, we found a stronger relationship between current, than past, OC use and hrHPV positivity (OR ex-users $v s$ never users 1.23 (95\% CI $0.99-1.51)$; OR current users $v s$ never users $1.46(95 \%$ 
CI 1.24-1.73)). This appears compatible with the postulated mechanisms by which current OC use influences infection, which include the enhancing effect of oestrogens on cervical ectopy, thereby permitting potential carcinogens (including HPV) easier access to the transformation zone (Green et al, 2003), and increased cell proliferation and transcription of HPV induced by direct hormonal effects on cervical cells (de Villiers, 2003).

\section{Reproductive history}

Our observation that having been pregnant was associated with reduced hrHPV infection risk is consistent with the IARC HPV Prevalence Surveys Study Group analysis of $>15000$ women (Vaccarella et al, 2006a). We found that the effect was stronger if a childbirth had resulted, and with older age at first pregnancy. In the United Kingdom, earlier age at first pregnancy or childbirth, and decreased likelihood of having an abortion, are associated with low socio-economic status (Smith, 1993; Wellings et al, 2001; ISD Scotland, 2006). However, our analysis was adjusted for tertiary education as a measure of socio-economic status. Although age at first pregnancy may be a marker for age at sexual debut, it is not as strongly predictive of HPV infection as previously thought (Vaccarella et al, 2006b). Possible explanations for this inverse association with pregnancy include breastfeeding, which results in high progesterone levels with atrophic changes and retraction of the squamocolumnar junction into the cervical canal, possibly reducing the likelihood of infection; alterations in patterns of sexual (e.g. changing partners, frequency of coitus) and other behaviours that influence infection risk (e.g. smoking).

\section{Age- and smear-stratified analyses}

Identifying differences in the relative importance of risk factors in sub-groups can be informative - as is evident from the few previous studies using this analytical approach (Lazcano-Ponce et al, 2001; Molano et al, 2002; Anh et al, 2003). We undertook ageand smear-stratified analyses because these were the most important risk factors, and they interacted, suggesting that the relative contribution of hrHPV infection, and other factors, in the aetiology of cytological abnormalities differs by age.

\section{ACKNOWLEDGEMENTS}

This study was nested within the TOMBOLA trial (ISRCTN 34841617). TOMBOLA is funded by the Medical Research Council and the NHS in England and Scotland. The TOMBOLA group comprises Grant-holders and Staff in clinical sites and coordinating centres. Grant holders: Current: Mark Avis, Maggie Cruickshank, Ian Duncan, Rob Hammond, David Jenkins, Jane Johnson, Julian Little (Former Principal Investigator), Graeme Murray, Keith Neal, David Parkin, Alistair Robertson, Ian Russell, Rashmi Seth, Linda Sharp, Louise Smart, Leslie Walker, Norman Waugh (Current Principal Investigator) and Dave Whynes. Former: Claire Chilvers, Katherine Fielding, Eric Walker. Staff in clinical sites and co-ordinating centres: Grampian: Breda Anthony, Sarah Bell, Massoud Boroujerdi, Adrienne Bowie, Katrina Brown, Joe Brown, Keng Chew, Claire Cochran, Seonaidh Cotton, Jeannie Dean, Kate Dunn, Jane Edwards, David Evans, Julie Fenty, Al Finlayson, Marie Gallagher, Nicola Gray, Kirsten Harrild, Maureen Heddle, Alison Innes, Debbie Jobson, Jayne MacGregor, Sheona Mackenzie, Amanda Mackie, John Norrie, Ike Okorocha, Morag Reilly, Joan Rodgers, Alison Thornton, Rachel Yeats. Tayside: Lindyanne Alexander, Lindsey Buchanan, Susan Henderson, Tine Iterbeke, Susanneke Lucas, Gillian Manderson, Sheila Nicol, Gael Reid, Carol Robinson, Trish Sandilands. Nottingham: Marg Adrian, Ahmed Al-Sahab, Hazel Brook, Claire Bushby, Rita Cannon, Brenda Cooper, Ruth Dowell, Mark Dunderdale, Dr Gabrawi, Li Guo, Lisa Heideman, Steve Jones, Salli Lawson, Zoë Philips, Christopher Platt, Shaku Prabhakaran, John Rippin, Rose Thompson, Elizabeth Williams, Claire Woolley. We are grateful to John Rippin and Li Guo for technical assistance with running the HPV assays, and to Nicola Gray for help with editing the manuscript.

\section{REFERENCES}

ALTS Group (2003) Results of a randomized trial on the management of cytology interpretations of atypical squamous cells of undetermined significance. Am J Obstet Gynecol 188: 1392

Anh PTH, Hieu NT, Herrero R, Vaccrella S, Smith JS, Thuy NY, Nga NH, Duc NB, Ashley R, Snijders PJF, Meijer CJLM, Munoz N, Parkin DM, Franceschi S (2003) Human papillomavirus infection among women in South and North Vietnam. Int J Cancer 104: 213-220

Bellis MA, Hughes K, Thomson R, Bennett A (2004) Sexual behaviour of young people in international tourist resorts. Sex Transm Infect 80: $43-47$

Bosch FX, Lorincz A, Munoz N, Meijer CJ, Shah KV (2002) The causal relation between human papillomavirus and cervical cancer. $J$ Clin Pathol 55: 244-265

Bosch ZF, Iftner T (2005) The aetiology of cervical cancer. NHS CSP Publication No 22

Brink AATP, Zielinski GD, Steenbergen RDM, Snijders PJF, Meijer CJLM (2005) Clinical relevance of human papillomavirus testing in cytopathology. Cytopathology 16: 7-12

Castle PE, Walker JL, Schiffman M, Wheeler CM (2005) Hormonal contraceptive use, pregnancy and parity, and the risk of cervical intraepithelial neoplasia 3 among oncogenic HPV DNA-positive women with equivocal or mildly abnormal cytology. Int J Cancer 117: 1007-1012

Cuschieri KS, Cubie HA, Whitley MW, Seagar AL, Arends MJ, Moore C, Gilkisson G, McGoogan E (2004) Multiple high risk HPV infections are common in cervical neoplasia and young women in a cervical screening population. J Clin Pathol 57: 68-72

Cuzick J, Szarewski A, Cubie H, Hulman G, Kitchener H, Luesley D, McGoogan E, Menon U, Terry G, Edwards R, Brooks C, Desai M, Gie C, Ho L, Jacobs I, Pickles C, Sasieni P (2003) Management of women who test positive for high-risk types of human papillomavirus: the HART study. Lancet 362: $1871-1876$

de Villiers EM (2003) Relationship between steroid hormone contraceptives and HPV, cervical intraepithelial neoplasia and cervical carcinoma. Int $J$ Cancer 103: $705-708$

Duncan ID (1997) Guidelines for Clinical Practice and Programme Management. Sheffield: National Health Service Cervical Screening Programme

Escobedo LG, Reddy M, DuRant RH (1997) Relationship between cigarette smoking and health risk and problem behaviors among US adolescents. Arch Pediatr Adolesc Med 151: 66-71

Fenton KA, Mercer CH, McManus CH, Erens B, Wellings K, Macdowall W, Bryon CL, Copas AJ, Nanchahal K, Field J, Johnson AM (2005) Ethnic variations in sexual behaviour in Great Britain and risk of sexually transmitted infections: a probability survey. Lancet 365: 1246-1255

Franceschi S, Herrero R, Clifford GM, Snijders PJF, Arslan A, Anh PTH, Bosch FX, Ferreccio C, Hieu NT, Lazcano-Ponce E, Matos E, Molano M, Qiao Y-L, Rajkumar R, Ronco G, de Sanjose S, Shin H-R, Sukvirach S, Thomas JO, Meijer CJLM, Munoz N, the IARC HPV Prevalence Surveys Study Group (2006) Variations in the age-specific curve of human papillomavirus prevalence in women worldwide. Int $J$ Cancer 119: $2677-2684$

Green J, Berrington de Gonzalez A, Smith JS, Franceschi S, Appleby P, Plummer M, Beral V (2003) Human papillomavirus infection and use of oral contraceptives. Br J Cancer 88: 1713-1720

Harper DM, Franco EL, Wheeler C, Ferris DG, Jenkins D, Schuind A, Zahaf T, Innis B, Naud P, De Carvalho NS, Roteli-Martins CM, Teixeira J, Blatter MM, Korn AP, Quint W, Dubin G (2004) Efficacy of a bivalent L1 viruslike particle vaccine in prevention of infection with human papillomavirus 
types 16 and 18 in young women: a randomised controlled trial. Lancet 364: $1757-1765$

Hibbitts S, Rieck GC, Hart K, Powell NG, Beukenholdt R, Dallimore N, McRea J, Hauke A, Tristram A, Fiander AN (2006) Human papillomavirus infection: an anonymous prevalence study in South Wales, UK. $\mathrm{Br} J$ Cancer 95: 226-232

Ho GYF, Bierman R, Beardsley L, Chang CJ, Burk RD (1998) Natural history of cervicovaginal papillomavirus infection in young women. $\mathrm{N} \mathrm{Engl} \mathrm{J}$ Med 338: $423-428$

Hosmer DW, Lemeshow S (1989) Applied Logistic Regression. New York: Wiley

International Agency for Research on Cancer (2005) Cervix Cancer Screening: IARC Handbooks of Cancer Prevention. Lyon: IARC Press

ISD Scotland (2006) Maternal Age. Available from: http://www.isdscotland. org/isd/info3.jsp?pContentID $=1436 \&$ p_applic $=$ CCC\&p_service $=$ Content . show\&. Accessed 6 February 2007

ISD Scotland (2007) Cervical Cytology Workload Statistics. Available from: http://www.isdscotland.org/cervical_screening Accessed 6 February 2007

Jacobs MV, Snijders PJ, van den Brule AJ (1997) A general primer GP5+/ GP6(+)-mediated PCR-enzyme immunoasasy method for rapid detection of 14 high-risk and 6 low-risk human papillomavirus genotypes in cervical scrapings. J Clin Microbiol 35: $791-795$

Jarvelaid M (2004) Adolescent tobacco smoking and associated psychosocial health risk factors. Scand J Prim Health Care 22: 50-53

Johnson AM, Mercer CH, Erens B, Copas AJ, McManus S, Wellings K, Fenton KA, Korovessis C, Macdowall W, Nanchahal K, Purdon S, Field J (2001) Sexual behaviour in Britain: partnerships, practices, and HIV risk behaviours, Lancet 358: $1835-1842$

Kitchener HC, Almonte M, Wheeler P, Desai M, Gilham C, Bailey A, Sargent A, Peto J (2006) HPV testing in routine cervical screening: cross sectional data from the ARTISTIC trial. Br J Cancer 95: 56-61

Koutsky L, Kiviat NB (1999) Genital human papillomaviruses. In Sexually Transmitted Diseases Holmes K, Mardh P, Sparling P, Lemon SM, Stamm WE, Piot P (eds) 3rd edn New York: McGraw-Hill, pp 347-359

Kulmala SM, Syrjanen S, Shabalova I, Petrovichev N, Kozachenko V, Podistov J, Ivanchenko O, Zakharenko S, Nerovjna R, Kljukina L, Branovskaja M, Grunberga V, Juschenko A, Tosi P, Santopietro R, Syrjanen K (2004) Human papillomavirus testing with the hybrid capture 2 assay and PCR as screening tools. J Clin Microbiol 42: 2470-2475

Lam TH, Stewart SM, Ho LM (2001) Smoking and high-risk sexual behavior among young adults in Hong Kong. J Behav Med 24: $503-518$

Lazcano-Ponce E, Herrero R, Munoz N, Cruz A, Shah KV, Alonso P, Hernandez P, Salmeron J, Hernandez M (2001) Epidemiology of HPV infection among Mexican women with normal cervical cytology. Int $J$ Cancer 91: $412-420$

Ley C, Bauer HM, Reingold A, Schiffman MH, Chambers JC, Tashiro CJ, Manos MM (1991) Determinants of genital human papillomavirus infection in young women. I Natl Cancer Inst 83: 997-1003

Molano M, Posso H, Weiderpass E, van den Brule AJC, Ronderos M, Franceschi S, Meijer CJLM, Arslan A, Munoz N (2002) Prevalence and determinants of HPV infection among Columbian women with normal cytology. Br J Cancer 87: 324-333

Moss SM, Gray A, Marteau T, Legood R, Henstock E, Maissi E (2004) Evaluation of HPV/LBC Cervical Screening Pilot Studies: Summary of Report to the Department of Health (Revised October 2004) Sheffield: National Health Service Cervical Screening Programme

Munoz N, Bosch FX, de Sanjose S, Herrero R, Castellsague X, Shah KV, Snijders PJF, Meijer CJLM (2003) Epidemiologic classification of human papillomavirus types associated with cervical cancer. $N$ Engl J Med 348: $518-527$

NHS Health and Social Care Information Centre (2005) Cervical Screening Programme, England: 2004-2005. Available from: http://www.ic.nhs.uk/ pubs/cervicscrneng2005 Accessed 6 February 2007

Nobbenhuis MAE, Meijer CJLM, Van Den Brule AJC, Rozendaal L, Voorhorst FJ, Risse EKJ, Verheijen RHM, Helmerhorst TJM (2001) Addition of high-risk HPV testing improves the current guidelines on follow-up after treatment for cervical intraepithelial neoplasia. $\mathrm{Br} J$ Cancer 84: 796 - 801
Osler M, Kjaer SK (1996) Determinants of smoking behaviour in random samples of Greenlandic and Danish women 20-39 years of age. Arctic Med Res 55: $62-68$

Sarian LO, Derchain SF, Pittal Dda R, Andrade LA, Morais SS, Figueiredo PG (2005) Human papillomavirus detection by hybrid capture II and residual or recurrent high-grade squamous cervical intraepithelial neoplasia after large loop excision of the transformation zone (LLETZ). Tumori 91: $188-192$

Shapiro S, Carrara H, Allan BR, Hoffman M, Rosenberg L, Kelly JP, Cooper DD, Williamson AL (2003) Hypothesis: the act of taking a papanicolaou smear reduces the prevalence of human papillomavirus infection: a potential impact on the risk of cervical cancer. Cancer Causes Control 14: $953-957$

Sikstrom B, Hellberg D, Nilsson S, Brihmer C, Mardh PA (1995) Contraceptive use and reproductive history in women with cervical human papillomavirus infection. Adv Contracept 11: 273-284

Smith T (1993) Influence of socioeconomic factors on attaining targets for reducing teenage pregnancies. BMJ 306: $1232-1235$

TOMBOLA Group (2006) Trial of management of borderline and other low grade abnormal smears (TOMBOLA): trial design. Contemp Clin Trials 27: $449-471$

Tonon SA, Picconi MA, Zinovich JB, Liotta DJ, Bos PD, Galuppo JA, Alonio LV, Ferreras JA, Teyssie AR (1999) Human papillomavirus cervical infection and associated risk factors in a region of Argentina with a high incidence of cervical carcinoma. Inf Dis Obstet Gynecol 7: 237-243

Vaccarella S, Franceschi S, Herrero R, Munoz N, Snijders PJF, Clifford GM, Smith JS, Lazcano-Ponce E, Sukvirach S, Shin H-R, de Sanjose S, Molano M, Matos E, Ferreccio C, Anh PTH, Thomas JO, Meijer CJLM, IARC HPV Prevalence Surveys Study Group (2006b) Sexual behaviour, condom use, and human papillomavirus: pooled analysis of the IARC HPV Prevalence Surveys. Cancer Epidemiol Biomarkers Prev 15: $322-326$

Vaccarella S, Herrero R, Dai M, Snijders PJF, Meijer CJLM, Thomas JO, Anh PTH, Ferreccio C, Matos E, Posso H, de Sanjose S, Shin H-R, Sukvirach S, Lazcano-Ponce E, Ronco G, Rajkumar R, Qiao Y-L, Munoz N, Franceschi S, IARC HPV Prevalence Surveys Study Group (2006a) Reproductive factors, oral contraceptive use, and human papillomavirus infection: pooled analysis of the IARC HPV Prevalence Surveys. Cancer Epidemiol Biomarkers Prev 15: $2148-2153$

Villa LL, Costa RL, Petta CA, Andrade RP, Ault KA, Giuliano AR, Wheeler CM, Koutsky LA, Malm C, Lehtinen M, Skjeldestad FE, Olsson SE, Steinwall M, Brown DR, Kurman RJ, Ronnett BM, Stoler MH, Ferenczy A, Harper DM, Tamms GM, Yu J, Lupinacci L, Railkar R, Taddeo FJ, Jansen KU, Esser MT, Sings HL, Saah AJ, Barr E (2005) Prophylactic quadrivalent human papillomavirus (types 6, 11, 16, and 18) L1 virus-like particle vaccine in young women: a randomised double-blind placebo-controlled multicentre phase II efficacy trial. Lancet Oncol 6: $271-278$

Walboomers JMM, Jacobs MV, Manos MM, Bosch FX, Kummer JA, Shah KV, Snijders PJF, Peto J, Meijer CJLM, Munoz N (1999) Human papillomavirus is a necessary cause of invasive cervical cancer worldwide. J Pathol 189: 12 - 19

Wellings K, Nanchahal K, Macdowall W, McManus S, Erens B, Mercer CH, Johnson AM, Copas AJ, Korovessis C, Fenton KA, Field J (2001) Sexual behaviour in Britain: early heterosexual experience. Lancet 358: $1843-1850$

Winer RL, Koutsky LA (2004) The epidemiology of human papillomavirus infections. In Cervical Cancer: from Etiology to Prevention Rohan TE, Shah KV (eds) Dordrecht, the Netherlands: Kluwer Academic Publishers, pp $143-185$

Winer RL, Lee SK, Hughes JP, Adam DE, Kiviat NB, Koutsky LA (2003) Genital human papillomavirus infection: incidence and risk factors in a cohort of female university students. Am J Epidemiol 157: 218-226

Woodman CBJ, Collins S, Winter H, Bailey A, Ellis J, Prior P, Yates M, Rollason TP, Young LS (2001) Natural history of cervical human papillomavirus infection in young women: a longitudinal cohort study. Lancet 357: 1831 - 1836

Xi LF, Koutsky LA (1997) Epidemiology of genital human papillomavirus infections. Bull Inst Pasteur 95: $161-178$ 